\title{
Motivational regulation strategies, academic self-concept, and cognitive learning strategies of university students: does academic self-concept play an interactive role?
}

\author{
Annette Lohbeck ${ }^{1}$ (D) Barbara Moschner ${ }^{2}$
}

Received: 5 March 2021 / Revised: 26 August 2021 / Accepted: 3 October 2021 /

Published online: 16 November 2021

(c) The Author(s) 2021, corrected publication 2022

\begin{abstract}
The present study aimed to examine the specific relations between five motivational regulation strategies (i.e., interest enhancement, environmental control, self-consequating, performance self-talk, mastery self-talk), academic self-concept, and three cognitive learning strategies (i.e., organization, elaboration, rehearsal) of 415 university students. A total of $n=238$ students were in the first year of their university program, while $n=178$ students were in the mid-term of their university program. Results of correlation analysis revealed that all five motivational regulation strategies were positively related to the three cognitive learning strategies. In contrast, regression analysis showed that organization was only significantly linked to interest enhancement, self-consequating, and performance self-talk, while elaboration was only significantly linked to self-consequating, and rehearsal was only significantly linked to interest enhancement and performance self-talk. Academic selfconcept proved to interact with interest enhancement in predicting elaboration. Furthermore, the measurement separability of the three constructs (i.e., motivational regulation strategies, academic self-concept, cognitive learning strategies) and measurement invariance across sample for the five motivational regulation strategies were also supported.
\end{abstract}

Keywords Motivational regulation strategies $\cdot$ Cognitive learning strategies $\cdot$ Academic self-concept · University students

University students' motivation increasingly declines during their university program (Corker et al., 2013; Henning \& Shulruf, 2011). A central question is therefore: How can university students regulate their motivation effectively to maintain or increase it? An

Annette Lohbeck

annette.lohbeck@uni-paderborn.de

Barbara Moschner

barbara.moschner@uni-oldenburg.de

1 Faculty of Educational Sciences, University of Paderborn, Warburger Str. 100, 33098 Paderborn, Germany

2 School of Educational and Social Sciences, Faculty of Educational Sciences, Carl Von Ossietzky University of Oldenburg, Ammerländer Heerstraße 114-118, 26129 Oldenburg, Germany 
accumulating number of studies have highlighted the great significance of university students' motivational regulation strategies for many educational outcomes (e.g., Grunschel et al., 2016; Kryshko et al., 2020; Park \& Yun, 2017, 2018; Schwinger \& Otterpohl, 2017; Yun \& Park, 2020). For instance, motivational regulation strategies have been found to be closely related to better engagement (Smit et al., 2017; Yun \& Park, 2020), more effort (Schwinger \& Otterpohl, 2017; Schwinger \& Stiensmeier-Pelster, 2012; Wolters, 1999), less procrastination (Grunschel et al., 2016; Ljubin-Golub et al., 2019; Wolters \& Benzon, 2013), and better academic achievement (Kryshko et al., 2020; Schwinger \& StiensmeierPelster, 2012; Schwinger et al., 2009). In contrast, little is still known about the relations of university students' specific motivational regulation strategies with their academic selfconcept, defined as self-perception of academic abilities (Brunner et al., 2010), and cognitive learning strategies that help students save the information in their long-term memory (Weinstein \& Meyer, 1991). For this reason, the present study aimed to examine the specific relations of university students' motivational regulation strategies to their academic self-concept, and cognitive learning strategies. The focus of this study was, in particular, on the investigation of the possible interaction of academic self-concept with specific motivational regulation strategies in predicting cognitive learning strategies. We believe that this research is essential because academic self-concept has been found to interact with numerous individual characteristics (Guo et al., 2015; Marsh et al., 2016). Figure 1 depicts the theoretical model under investigation. By disentangling the relations between university students' specific motivational regulation strategies, academic self-concept, and cognitive learning strategies, this study advances understanding of the underlying motivational processes of university students' learning and provides practical conclusions on how to promote university students' motivational regulation strategies that are necessary to maintain or increase their motivation during their university program.

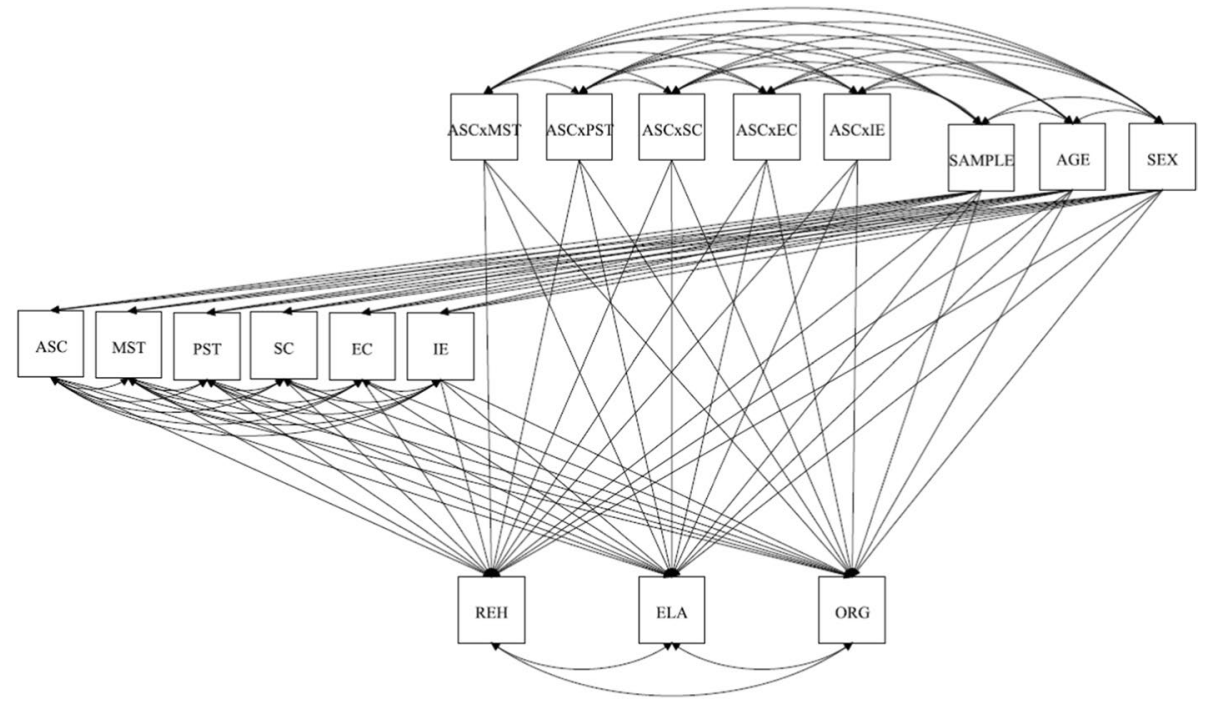

Fig. 1 Theoretical model under investigation. Notes. ASC, academic self-concept; MST, mastery self-talk; PST, performance self-talk; SC, self-consequating; EC, environmental control; IE, interest enhancement; REH, rehearsal; ELA, elaboration; ORG, organization 


\section{Conceptual framework}

In the present study, we selected the following five motivational learning strategies based on their salience in the literature (Schwinger \& Stiensmeier-Pelster, 2012; Schwinger et al., 2007, 2009; Steuer et al., 2019; Teng \& Zhang, 2018; Wolters, 1999): (1) Interest enhancement is a strategy used to maintain or increase one's own interest in the tasks, by, for instance, attaching more value on the tasks (Wolters, 1999). (2) Environmental control refers to students' control for their learning surrounding; that is, for instance, working in a quiet or tidy place (Wolters, 1999). (3) Self-consequating relates to the consequences of a behavior, such as rewards or punishments (Zimmerman \& Pons, 1986), and (4) performance self-talk as well as (5) mastery self-talk encompass all goal-oriented self-verbalizations pertaining to the intention to enlarge one's own performance and master challenging tasks (Schwinger et al., 2007). Furthermore, we focused on the following three cognitive learning strategies as outcomes of those five motivational regulation strategies (Marton \& Säljö, 1984; Valentín et al., 2013; Weinstein et al., 2011): (1) Organization refers to all strategies that help structuring the learning material, by, for instance, creating mind maps and diagrams, or highlighting specific passages within the text. (2) Elaboration involves all strategies that make information more retrievable with the help of prior knowledge and mnemonic techniques, such as creating analogies or writing summaries. Finally, (3) rehearsal relates to all strategies used to gain or increase knowledge by simply repeating information. While organization and elaboration are considered as deep-level strategies, rehearsal is also seen as a more superficial learning strategy (VanderStoep \& Pintrich, 2008).

To disentangle the relations of those five motivational regulation strategies with academic self-concept and the three cognitive learning strategies, we relied on the motivational regulation model proposed by Schwinger and Stiensmeier-Pelster (2012). This model describes three phases of the motivational regulation process that maintain or increase students' motivation: In the first phase, students need to recognize their motivational deficit and to increase their motivation. In the second phase, when students decided to increase their motivation, they need to identify the reasons for their motivational deficit, and in the third phase, they need to select and use the adequate motivational regulation strategy (Schwinger \& Stiensmeier-Pelster, 2012). Because students need to reflect on their competencies in all three phases of this motivational regulation process, it is reasonable that students who feel competent in their tasks (i.e., have a high academic self-concept) and more confident in selecting and using motivational regulation strategies report a more frequent use of cognitive learning strategies. However, to the best of our knowledge, no studies so far have yet investigated the interplay of students' specific motivational regulation strategies, academic self-concept, and cognitive learning strategies simultaneously.

\section{Relations between motivational regulation strategies, academic self-concept, and cognitive learning strategies}

Some studies have shown that motivational regulation strategies are positively related to students' self-reported use of cognitive learning strategies (e.g., Anais et al., 2012; Park \& Yun, 2017; Schwinger et al., 2007; Teng \& Zhang, 2018; Wolters, 1999; Wolters \& Benzon, 2013). However, very rarely has it yet been explored whether specific motivational 
regulation strategies are also related to specific cognitive learning strategies. For instance, Wolters and Benzon (2013) measured six motivational regulation strategies (i.e., regulation of value, regulation of performance goals, self-consequating, environmental structuring, regulation of situational interest, regulation of mastery goals) and three cognitive learning strategies (i.e., organization, elaboration, rehearsal), but considered only a global factor of the three cognitive learning strategies. Results showed consistently positive relations of all six motivational regulation strategies to this global factor of cognitive learning strategies. In contrast, Schwinger et al. (2007) considered all five motivational regulation strategies (i.e., interest enhancement, environment control, self-consequating, performance self-talk, mastery self-talk) and three cognitive learning strategies (i.e., organization, elaboration, rehearsal) specifically, which were also selected for the present study. However, results yielded only some significantly positive relations between the five motivational regulation strategies and three cognitive learning strategies: Interest enhancement was positively related to organization and elaboration but not to rehearsal, while performance self-talk and self-consequating were positively related to organization as well as rehearsal, and mastery self-talk as well as environmental control were unrelated to all three cognitive learning strategies. Furthermore, there is also evidence (e.g., Park \& Yun, 2017; Teng \& Zhang, 2018; Wolters, 1999) that some specific motivational regulation strategies significantly influence cognitive learning strategies. For instance, Park and Yun (2017) found that surface level strategy (i.e., rehearsal) was positively predicted by enhancement of situational interest, mastery self-talk, and performance avoidance self-talk, while deep processing strategy (i.e., elaboration) was positively predicted by enhancement of situational interest, enhancement of personal significance, and mastery self-talk. In contrast, Wolters (1999) reported that only performance self-talk and self-consequating had a positive impact on rehearsal, while the other three motivational regulation strategies (i.e., interest enhancement, environmental control, mastery self-talk) did not affect cognitive learning strategies. These findings propose very differential links of the five motivational regulation strategies to the three cognitive learning strategies.

Another potential precursor of students' self-reported cognitive learning strategies is academic self-concept. Several studies have shown that academic self-concept influenced cognitive learning strategies (e.g., Chen et al., 2015; Du, 2012; Karlen, 2016; McInerney et al., 2012; Ning \& Downing, 2015; Ommundsen et al., 2005; Rodriguez, 2009). For instance, McInerney et al. (2012) found that students' self-concept in English positively predicted their self-reported deep-level strategies (i.e., elaboration, organization) and surface learning strategies (i.e., rehearsal). Similarly, Chen et al. (2015) reported that students' academic self-concept positively affected their deep, surface, and strategic approaches. Following up on this research, we sought to explore the possible impact of students' specific motivational regulation strategies and academic self-concept on their self-reported use of cognitive learning strategies.

\section{Interaction of academic self-concept and motivational regulation strategies}

Until now, there is still no evidence for a possible interaction of academic self-concept with specific motivational regulation strategies in predicting cognitive learning strategies. In contrast, numerous studies have provided support for a significant interaction of academic self-concept with subjective task values in predicting educational outcomes 
(e.g., Guo et al., 2015; Marsh et al., 2016; Trautwein et al., 2012). A central theoretical rationale for this interaction is, in particular, the well-established expectancy-value theory (EVT; Eccles, 2009; Eccles \& Wigfield, 2020). This theory posits that high expectancies of success (i.e., academic self-concepts) are not sufficient to motivate a behavior (cf. Guo et al., 2015). Rather, it is also necessary that students place high values on the tasks; thus, only the combination of high expectancies of success and high task values leads to more motivation. In line with this assumption, we had reasons to speculate that students' academic self-concept would also interact with their self-reported use of motivational regulation strategies because selecting and using motivational regulation strategies also implies the subjective valuing of tasks. For instance, students need to place intrinsic value on the tasks, which is needed for interest enhancement, while they also need to perceive the costs, such as effort, which is, for instance, required for controlling for the learning environment. Another theoretical reasoning for this possible interaction of academic self-concept with the five motivational regulation strategies is also the motivational regulation model by Schwinger and Stiensmeier-Pelster (2012). On the one hand, students need to reflect on their competencies in all three phases of the motivational regulation process, and on the other hand, they also need to feel confident in selecting and using motivational regulation strategies when aiming at improving their learning behavior. For instance, students who perceive high competencies and feel competent in enhancing their interest may be more motivated in structuring, elaborating, and repeating the learning material. In contrast, the less competent students perceive themselves to be and the less confident they feel in selecting adequate motivational regulation strategies, the less motivated they may also be in regulating and improving their learning process. Alternatively, it is also reasonable that students who feel very competent in their tasks may also believe that it is not worth to motivate themselves because they always perform well. As a consequence, these students would probably make less effort to structure, elaborate, or repeat the learning material. By implication, the combination of a more positive academic self-concept and a more frequent use of motivational regulation strategies may be needed for the selection and adequate use of cognitive learning strategies.

In sum, there are several plausible theoretical reasons to assume that students' academic self-concept also interacts with their motivational regulation strategies, even though there is still no evidence for this possible interaction in the literature. For this reason, we strived to go beyond previous literature by exploring the possible interaction of academic self-concept with the five motivational regulation strategies in predicting the three cognitive learning strategies selected for this study.

\section{The present study}

Based on the motivational regulation model by Schwinger and Stiensmeier-Pelster (2012) and EVT (Eccles, 2009; Eccles \& Wigfield, 2020), the central objective of the present study was to explore the specific relations between five motivational regulation strategies (i.e., interest enhancement, environment control, self-consequating, performance self-talk, mastery self-talk), academic self-concept, and three cognitive learning strategies (i.e., organization, elaboration, rehearsal) of university students. In this respect, we aimed to test the following three hypotheses based on the theoretical and empirical framework reviewed: 
Hypothesis 1 (relations of motivational regulation strategies): We assumed that all five motivational regulation strategies would be positively related to the three cognitive learning strategies (Anais et al., 2012; Park \& Yun, 2017; Schwinger et al., 2007; Teng \& Zhang, 2018; Wolters, 1999; Wolters \& Benzon, 2013).

Hypothesis 2 (relations of academic self-concept): We hypothesized that academic self-concept would positively relate to the three cognitive learning strategies (Chen et al., 2015; Du, 2012; Karlen, 2016; McInerney et al., 2012; Ning \& Downing, 2015; Ommundsen et al., 2005; Rodriguez, 2009).

Hypothesis 3 (interactions): In line with the motivational regulation model (Schwinger \& Stiensmeier-Pelster, 2012) and EVT framework (Eccles, 2009; Guo et al., 2015; Marsh et al., 2016; Trautwein et al., 2012), we expected that academic self-concept would also interact with the five motivational regulation strategies in predicting the three cognitive learning strategies; that is: students high in academic self-concept and high in the five motivational regulation strategies were assumed to report a more frequent use of the three cognitive learning strategies than students low in academic selfconcept and low in the five motivational regulation strategies.

When testing these three hypotheses, we additionally controlled for university students' sex, age, and number of semesters because the use of motivational regulation strategies may also vary by several situational and personal factors (Schwinger \& Stiensmeier-Pelster, 2012).

\section{Method}

\section{Sample and procedure}

The sample of this study consisted of 415 university students (females: $n=327$ ) from two universities in Germany. Of these, $n=238$ students were in the first year of their university program, while $n=178$ students were in the mid-term of their university program. Students' mean age was $22.38(S D=2.48)$. All participants filled out the questionnaires voluntarily during their courses at university and were informed that their data would be treated anonymously. Data collection took place during October 2015 and December 2015.

\section{Measures}

\section{Motivational regulation strategies}

The five specific motivational regulation strategies were measured with a questionnaire developed by Schwinger et al. (2007). This questionnaire consists of 25 items and five scales: (1) interest enhancement (IE, 4 items, e.g., "I make learning more pleasant for me by trying to arrange it playfully," $\alpha=0.81$ ), (2) environment control (EC, 3 items, e.g., "I make sure that distractions occur as seldom as possible," $\alpha=0.73$ ), (3) self-consequating (SC; 8 items, e.g., "I tell myself that after work I can do something nice, if I first keep on learning now," $\alpha=0.82$ ), (4) performance self-talk (PST, 5 items, e.g., "I remind myself about how important it is to get good grades," $\alpha=0.84$ ), and (5) mastery self-talk (MST, 4 items, e.g., "I persuade myself to work intensely for the sake of learning," $\alpha=0.73$ ). All items were rated on a 5-point scale ranging from 1 (rarely) to 5 (very often). 


\section{Cognitive learning strategies}

To measure the three cognitive learning strategies, three scales from the Learning Strategies in Studies questionnaire developed by Wild and Schiefele (1994) were used: (1) rehearsal (6 items; e.g., "I memorize rules, technical terms, or formulas," $\alpha=0.81$ ), (2) elaboration (8 items; e.g., "I wonder if the material is important for my daily life," $\alpha=0.84$ ), and (3) organization (8 items; e.g., "I make tables, diagrams, or graphs to have the material better structured," $\alpha=0.79$ ). All responses to the items were made on a 6-point scale ranging from 1 (completely disagree) to 6 (completely agree).

\section{Academic self-concept}

Students' academic self-concept was assessed with a scale developed for the PALEA study (Kauper et al., 2012). This scale comprises four positively worded items (e.g., "I am good at my subjects," $\alpha=0.77)$. In the introduction of this scale, it was emphasized that all items should be referred to the university program to avoid confounding with students' general abilities in their private life. All items were evaluated on a 4-point response scale ranging from 1 (strongly disagree) to 4 (strongly agree).

\section{Data analysis}

First, as a prerequisite for all analyses, the measurement separability of all three constructs (i.e., motivational regulation strategies, academic self-concept, cognitive learning strategies) was tested. For this purpose, the following four factor models were estimated using confirmatory factor analysis (CFA): (1) a 1-factor CFA model vs. (2) a 5-factor CFA model for the five motivational regulation strategies, (3) a 1-factor CFA model for academic selfconcept, and (4) a 3-factor CFA model for the three cognitive learning strategies.

Second, to reveal whether the measurement of the five motivational regulation strategies is theoretically possible in an identical manner across the two samples (i.e., first-year students vs. students in the mid-term of their university program), the measurement invariance across sample for the five motivational regulation strategies was tested. In this respect, the following four invariance models were contrasted to each other: (a) configural (i.e., same factor structure), (b) metric (i.e., same factor loadings), (c) scalar (i.e., same item intercepts), and (d) strict (i.e., same measurement errors). To evaluate the fit of the models, the chi-square statistic with its degrees of freedom, the comparative fit index (CFI), the Tucker-Lewis index (TLI), and the root mean square error of approximation (RMSEA) with its confidence interval were analyzed. An adequate model fit was assumed with CFI and TLI values $>0.90$ and RMSEA values $>0.05$ (Hu \& Bentler, 1999). Furthermore, to test for significant changes of model fit, the Satorra-Bentler scaled chi-square difference test and the criteria proposed by Cheung and Rensvold (2002) were used, that is: the CFI and TLI values should not decrease by more than 0.01 and the RMSEA values should not increase by more than 0.015 .

Third, to find answers to the specific relations between the five motivational regulation strategies, academic self-concept, and three cognitive learning strategies, both correlation and regression analyses were performed. In the regression analysis, two models were tested in which the five motivational regulation strategies and academic self-concept were considered as independent variables of the three cognitive learning strategies, 
with sex, age, and the sample as control variables. In the first model (Model 9), all three cognitive learning strategies were regressed on all five motivational regulation strategies, academic self-concept, and the control variables (sex, age, sample). Finally, in the second model (Model 10) exploring the possible interaction of academic self-concept with the five motivational regulation strategies, all product terms of academic self-concept with each of the five motivational regulation strategies were added to the model simultaneously. All regression models were estimated with manifest variables in Mplus 8.6 (Muthén \& Muthén, 1998-2021) using the robust maximum likelihood estimator (MLR) and the full information maximum likelihood approach (FIML). The amount of missing data ranged from 0 to $1.2 \%$ on the item level.

\section{Results}

\section{Measurement separability and invariance testing}

Table 1 presents the results of CFA and measurement invariance testing across the two samples of university students (i.e., first-year students vs. students in the mid-term of their university program).

Results of CFA provided strong support for the 5-factor CFA model of the five motivational regulation strategies (see M2 in Table 1). The 5-factor CFA model showed a significantly better fit to the data than the 1 -factor CFA model $\left(\Delta \chi^{2}=1131.162, \Delta d f=10\right.$, $p<0.001)$. All five factors of the 5 -factor CFA model were well defined by adequate factor loadings $(>0.30 ; \lambda=0.383-0.859)$. For this reason, the 5 -factor CFA model was selected for further analysis. Similarly, the 1-factor structure of academic self-concept was also adequately reproduced by a 1 -factor CFA model (see M3 in Table 1) and all three cognitive learning strategies were clearly empirically separable from each other (see M4 in Table 1). Furthermore, all invariance models for the five motivational regulation strategies exhibited a good fit to the data. No invariance testing fell outside the range of variation permissible for the assumption of multi-group invariance.

\section{Descriptive statistics and correlations}

Table 2 provides descriptive statistics (means, standard deviations) and correlations of all variables selected for this study.

All motivational regulation strategies were significantly positively related to each other. Only self-consequating and performance self-talk were not significantly interrelated. As expected in Hypotheses 1 and 2, the five motivational regulation strategies and academic self-concept showed positive correlations with the three cognitive learning strategies. However, not all correlations were substantial; namely: the correlations of elaboration with interest enhancement and performance self-talk as well as between rehearsal and self-consequating. Furthermore, academic self-concept was significantly positively related to organization and elaboration. The correlations of self-consequating and mastery self-talk with academic self-concept were also substantial, while the other three motivational regulation strategies were not substantially related to academic self-concept. 


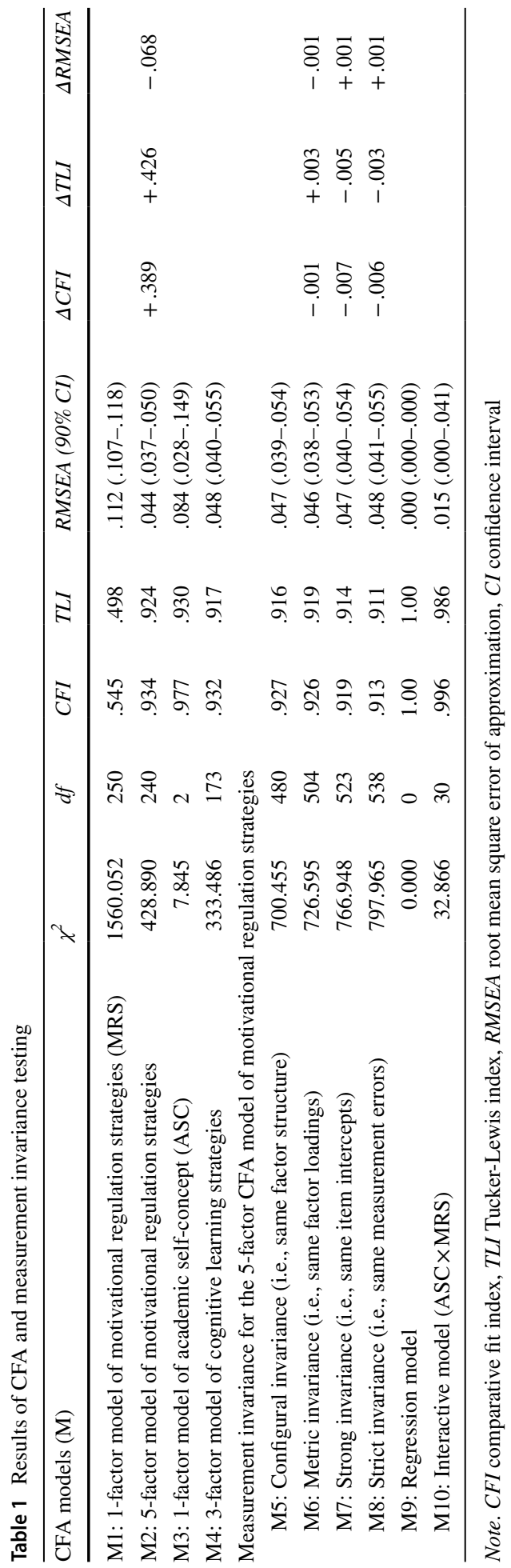


Table 2 Descriptive statistics (means, standard deviations) and correlations

\begin{tabular}{llllllllll}
\hline & $M(S D)$ & EC & SC & PST & MST & ORG & ELA & REH & ACS \\
\hline Interest enhancement (IE) & $3.64(0.91)$ & $.23^{* *}$ & $.26^{* * *}$ & $.49^{* * *}$ & $.46^{* * *}$ & $.36^{* * *}$ & .09 & $.34^{* * *}$ & .11 \\
Environment control (EC) & $3.06(0.96)$ & - & $.19^{* *}$ & $.37^{* * *}$ & $.45^{* * *}$ & $.19^{* *}$ & $.18^{* *}$ & $.20^{* *}$ & .04 \\
Self-consequating (SC) & $2.56(0.71)$ & & - & .05 & $.51^{* * *}$ & $.30^{* * *}$ & $.69^{* * *}$ & .03 & $.26^{* * *}$ \\
Performance self-talk (PST) & $3.53(0.82)$ & & & - & $.61^{* * *}$ & $.38^{* * *}$ & .07 & $.45^{* * *}$ & .08 \\
Mastery self-talk (MST) & $2.86(0.79)$ & & & & - & $.33^{* * *}$ & $.27^{* * *}$ & $.31^{* * *}$ & $.18^{*}$ \\
Organization (ORG) & $3.99(0.96)$ & & & & & - & $.44^{* * *}$ & $.71^{* * *}$ & $.18^{*}$ \\
Elaboration (ELA) & $3.59(0.95)$ & & & & & & - & .03 & $.19^{* *}$ \\
Rehearsal (REH) & $4.45(0.94)$ & & & & & & & - & .02 \\
Academic self-concept (ACS) & $2.69(0.53)$ & & & & & & & - \\
\hline
\end{tabular}

Note. $* * * p<.001, * * p<.01, * p<.05$

\section{Regression analysis}

Table 3 presents the results of the regression model (M9) testing the partial correlations between the five motivational regulation strategies, academic self-concept, and three cognitive learning strategies, with sex, age, and the sample as control variables.

While academic self-concept was non-significantly linked to the three cognitive learning strategies, there were significantly positive regression paths from (a) interest enhancement to organization and rehearsal, (b) self-consequating to organization and elaboration, and (c) performance self-talk to organization and rehearsal. In addition, female students reported a significantly lower academic self-concept and significantly higher levels of interest enhancement, performance self-talk, mastery self-talk, organization, and rehearsal than male students. Younger students, in turn, stated a more frequent use of organization and rehearsal strategies than older students. Finally, students in the mid-term of their university program showed a more positive academic self-concept and reported a more frequent use of organization but less frequent use of mastery self-talk than first-year students. The amount of explained variance was 0.23 for organization, 0.36 for elaboration, and 0.21 for rehearsal. Due to the manifest variables, the fit of this model was excellent $\left(\chi^{2}=0.000, d f=0, C F I=1.000, T L I=1.000, R M S E A=0.000[0.000-0.000]\right.$, see M9 in Table 1).

When adding the interaction terms of academic self-concept with each of the five motivational regulation strategies to the model (M10) simultaneously, results revealed almost the same significant predictor-outcome relations as in Model 9. Table 4 presents the results of the interactive model under investigation (M10). In support of Hypothesis 3, academic self-concept significantly interacted with interest enhancement in predicting elaboration, indicating that students with a more positive academic self-concept and a high level of interest enhancement reported a more frequent use of elaboration $(\beta=0.12, p<0.05)$. In contrast, the other interaction terms were not substantial. The explained variance in the outcomes was almost equal to that of Model 9, that is: $R^{2}=0.23$ for organization, $R^{2}=0.37$ for elaboration, and $R^{2}=0.22$ for rehearsal. The fit of this interactive model was very good $\left(\chi^{2}=32.866, d f=30, C F I=0.996, T L I=0.986, R M S E A=0.015[0.000-0.041]\right.$, see M10 in Table 1). 


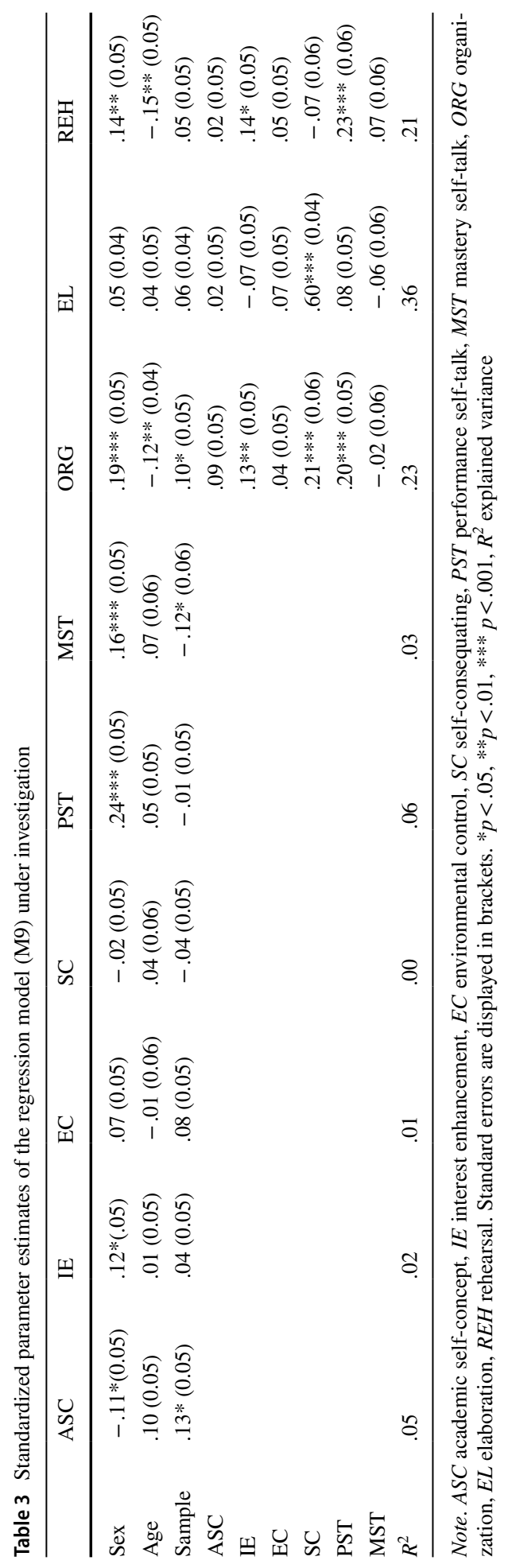




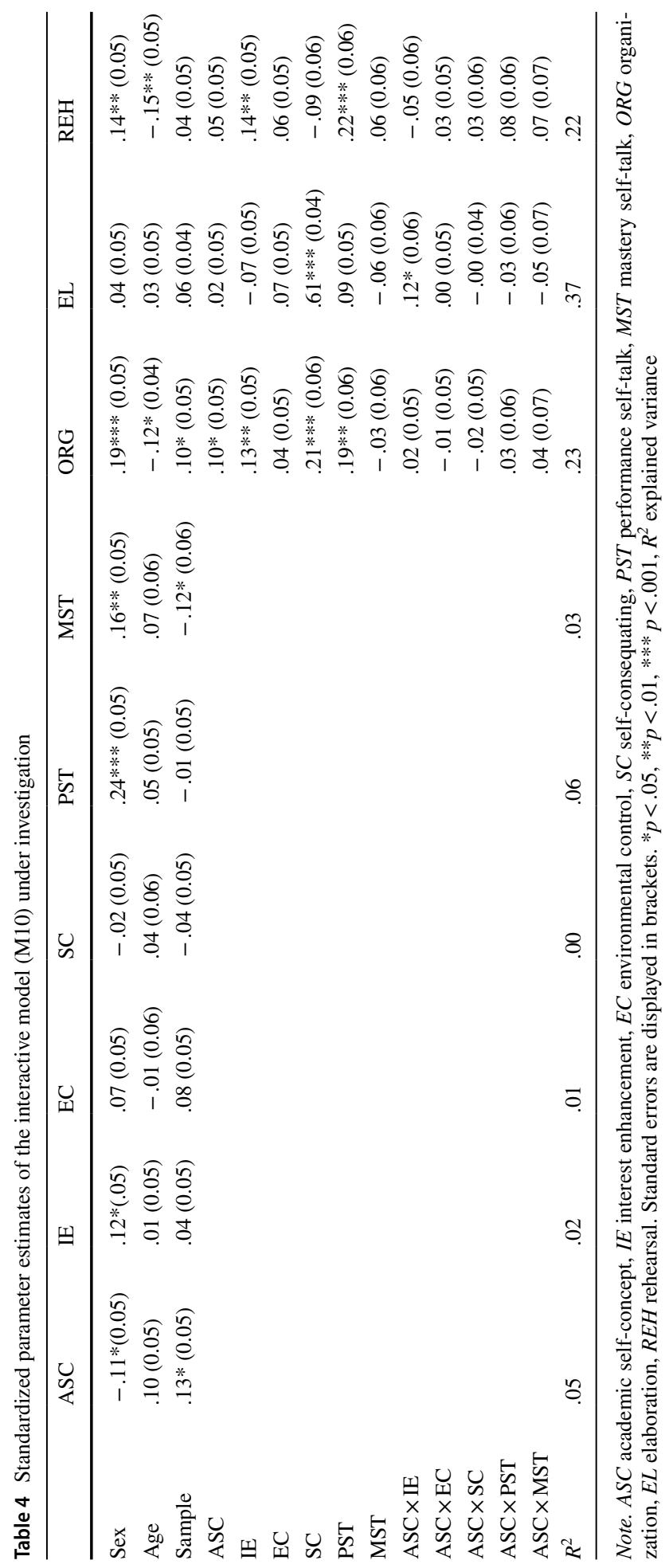




\section{Discussion}

The present study is unique in examining the specific relations between five motivational regulation strategies (i.e., interest enhancement, environment control, self-consequating, performance self-talk, mastery self-talk), academic self-concept, and three cognitive learning strategies (i.e., organization, elaboration, rehearsal) of university students. Furthermore, beyond this central objective, the measurement separability of all three constructs and the measurement invariance across sample (i.e., first-year students vs. students in the mid-term of their university program) for the five motivational regulation strategies were also tested.

In support of previous research (e.g., Schwinger \& Stiensmeier-Pelster, 2012; Schwinger et al., 2007, 2009; Wolters, 1999), results of CFA provided strong support for a clear separation of the three constructs selected for this study and for full measurement invariance for the five motivational regulation strategies. Latent mean-levels comparisons and manifest mean-levels based on summed/averaged scores of the five motivational regulation strategies are thus valid across first-year students and students in the mid-term of their university program.

As suggested in Hypothesis 1 and earlier shown in some studies (e.g., Pintrich \& Garcia, 2012; Teng \& Zhang, 2018; Wolters, 1999), all five motivational regulation strategies were positively related to the three cognitive learning strategies. However, not fully consistent with Hypothesis 2, academic self-concept was only significantly positively related to organization and elaboration but not to rehearsal. A possible reason for this result may be that rehearsal only targets at simply repeating information and may thus be less connected with students' real competencies. Furthermore, there were no significant correlations of rehearsal with self-consequating as well as of elaboration with interest enhancement and performance self-talk. The non-significant correlation of rehearsal with self-consequating may be due to the fact that rehearsal is more strongly related to acquiring basic knowledge, while self-consequating is more strongly linked to the consequences of learning. In contrast, the non-significant correlation of elaboration with performance self-talk may be explained by the item contents because the items for performance self-talk are directly referred to students' academic performance, while the items for elaboration are not explicitly referred to students' academic performance. Moreover, the non-significant correlation of elaboration with interest enhancement may result from the fact that elaboration is a deep-level strategy that requires prior knowledge, while interest enhancement is a more superficial strategy that may be more closely linked to the learning material rather than to the learning process (Marton \& Säljö, 1984; Valentín et al., 2013; Weinstein et al., 2011). These findings indicate that the five motivational regulation strategies are very differentially related to the three cognitive learning strategies.

Finally, results of regression analysis revealed significantly positive regression paths from (a) organization to interest enhancement, self-consequating, and performance selftalk, (b) elaboration to self-consequating, and (c) rehearsal to interest enhancement and performance self-talk. These results suggest that it is especially self-consequating that plays a crucial role for university students' self-reported use of organization and elaboration. This is a novel finding which is not consistent with that reported by Wolters (1999) who found only a significantly positive effect of self-consequating on rehearsal. A possible reason for these contradictory findings may be the different data set because Wolters (1999) used data of school students from grades 9 to 10 . By implication, it seems that university students use different motivational regulation strategies than school students. 
When exploring the possible interaction of academic self-concept with the five motivational regulation strategies, there was only a single interaction of academic self-concept with interest enhancement in predicting elaboration strategies, indicating that students with a higher academic self-concept and a higher perceived interest enhancement reported a more frequent use of elaboration. This result is also in line with Hypothesis 3 and some earlier studies in the EVT framework (e.g., Guo et al., 2015; Marsh et al., 2016; Trautwein et al., 2012) stating that academic self-concept as an indicator of expectancy of success interacts with intrinsic values. In contrast, there were no significant interactions between academic self-concept and the other four motivational regulation strategies in this investigation. These results propose that only interest enhancement involves a high subjective valuing of tasks but not the other four motivational regulation strategies.

\section{Limitations}

Some limitations must be mentioned: A first limitation concerns the sample of this study because most of the students were female students. Further research must therefore use more heterogenous samples to increase the generalizability of the reported findings. Of great concern is also the cross-sectional design, which does not permit any causal inferences and calls for the need of longitudinal studies. Furthermore, the number of predictor variables was relatively small, leading to only a small amount of explained variance in the regression. Future studies should consider more possible predictor variables of students' motivational regulation strategies and cognitive learning strategies. Of great interest is particularly the domain-specificity of motivational regulation strategies and cognitive learning strategies because the use of motivational regulation strategies and cognitive learning strategies may probably also differ across university students' subjects. Beyond the measurement of the constructs selected for this study, further studies should especially also measure students' real performance in their subjects over several periods of time or over the course of a year.

\section{Conclusions}

Despite the limitations mentioned, the present study showed the following three central findings: The five specific motivational regulation strategies are (1) empirically separable from each other, (2) invariant across sample, and (3) differentially related to the three cognitive learning strategies. Specifically, our results suggest that it is primarily interest enhancement, self-consequating, and performance self-talk that play a significant role in predicting university students' self-reported use of cognitive learning strategies. While interest enhancement, self-consequating, and performance self-talk play an important role for university students' self-reported use of organization, only self-consequating seems to be of significance for their self-reported use of elaboration strategies, and only interest enhancement and self-consequating seem to be relevant for their self-reported use of rehearsal strategies. These three motivational regulation strategies may thus be most beneficial for university students' use of cognitive learning strategies and should be promoted 
in the university program. A promising approach for promoting motivational regulation strategies is, in particular, virtual avatar-provided scaffolding in which virtual avatars (i.e., pedagogical agents) encourage online students to initiate their motivational needs and to use specific motivational regulation strategies. Several studies have already provided support for the great effectiveness of those virtual avatar trainings (e.g., Park, 2015; Park \& Lim, 2020). In addition, the most striking result of this research was the interaction of academic self-concept with interest enhancement in predicting university students' self-reported use of elaboration indicating that a more positive academic self-concept and a higher perceived interest enhancement determine university students' use of elaboration strategies. Finally, an important implication of this result is that supporting university students' academic selfconcept and interest enhancement may increase their use of elaboration strategies, which have been found as most influencing for many academic outcomes (Valentín et al., 2013; Weinstein et al., 2011). Some effective strategies for supporting university students' academic self-concept are, for instance, setting achievable and challenging goals, emphasizing the value and utility of the tasks, providing solution-based and internally focused feedback, and evaluating their performance directly, objectively, and transparently (Blegur et al., 2018; Craven et al., 1991).

Author contribution All authors contributed to the study conception and design. Conceptualization: Annette Lohbeck and Barbara Moschner; methodology: Annette Lohbeck; formal analysis and investigation: Annette Lohbeck; writing-original draft preparation: Annette Lohbeck; writing-review and editing: Barbara Moschner.

Funding Open Access funding enabled and organized by Projekt DEAL.

Availability of data and material Upon request, the authors can send relevant documentation of the data and material.

Code availability The authors make sure that all data and materials as well as software application or custom code support their published claims and comply with field standards.

\section{Declarations}

Ethics approval and consent to participate The authors certify that all procedures performed in this study were in accordance with the ethical standards of the institutional and/or national research committee and with the 1964 Helsinki Declaration and its later amendments or comparable ethical standards. Informed consent was obtained from all participants included in the study.

Consent for publication The authors affirm that all participants were informed about the purpose of this study and provided informed consent for publication the results of this study.

Conflict of interest The authors declare no competing interests.

Open Access This article is licensed under a Creative Commons Attribution 4.0 International License, which permits use, sharing, adaptation, distribution and reproduction in any medium or format, as long as you give appropriate credit to the original author(s) and the source, provide a link to the Creative Commons licence, and indicate if changes were made. The images or other third party material in this article are included in the article's Creative Commons licence, unless indicated otherwise in a credit line to the material. If material is not included in the article's Creative Commons licence and your intended use is not permitted by statutory regulation or exceeds the permitted use, you will need to obtain permission directly from the copyright holder. To view a copy of this licence, visit http://creativecommons.org/licenses/by/4.0/. 


\section{References}

Anais, M., Hojas, A., Bustos, A., Letelier, C., Zuzulich, M., Cabieses, B., \& Zubiaguirre, M. (2012). Motivational and cognitive learning strategies used by first-year engineering undergraduate students at Universidad Católica in Chile. Creative Education, 3, 811-817. https://doi.org/10.4236/ce.2012.326121.

Blegur, J., Wasak, M. R. P., \& Pabala, P. (2018). Students' academic self-concept: A founding strategy in learning process. The International Journal of Indian Psychology, 6, 45-54. https://doi.org/10.25215/ 0604.046

Brunner, M., Keller, U., Dierendonck, C., Reichert, M., Ugen, S., Fischbach, A., \& Martin, R. (2010). The structure of academic self-concepts revisited: The nested Marsh/Shavelson model. Journal of Educational Psychology, 102, 964-981. https://doi.org/10.1037/a0019644.

Chen, B. H., Chiu, W. C., \& Wang, C. C. (2015). The relationship among academic self-concept, learning strategies, and academic achievement: A case study of national vocational college students in Taiwan via SEM. The Asia-Pacific Education Researcher, 24(2), 419-431. https://doi.org/10.1007/ s40299-014-0194-1.

Cheung, G. W., \& Rensvold, R. B. (2002). Evaluating goodness-of-fit indexes for testing measurement invariance. Structural Equation Modeling, 9, 233-255. https://doi.org/10.1207/S15328007SEM0902_5.

Corker, K. S., Donnellan, M. B., \& Bowles, R. P. (2013). The development of achievement goals throughout college: Modeling stability and change. Personality and Social Psychology Bulletin, 39, 1404-1417. https://doi.org/10.1177/0146167213494243.

Craven, R. G., Marsh, H. W., \& Debus, R. L. (1991). Effects of internally focused feedback and attributional feedback on enhancement of academic self-concept. Journal of Educational Psychology, 83, 17-27. https://doi.org/10.1037/0022-0663.83.1.17.

Du, M. (2012). A study of the relationship between English self-concept and language learning strategies. Journal of Language Teaching and Research, 3(3), 508-517. https://doi.org/10.4304/jltr.3.3.508-51.

Eccles, J. S. (2009). Who am I and what am I going to do with my life? Personal and collective identities as motivators of action. Educational Psychologist, 44(2), 78-89. https://doi.org/10.1080/0046152090 2832368.

Eccles, J. S., \& Wigfield, A. (2020). From expectancy-value theory to situated expectancy-value theory: A developmental, social cognitive, and sociocultural perspective on motivation. Contemporary Educational Psychology, 61, 101859. https://doi.org/10.1016/j.cedpsych.2020.101859.

Grunschel, C., Schwinger, M., Steinmayr, R., \& Fries, S. (2016). Effects of using motivational regulation strategies on students' academic procrastination, academic performance, and well-being. Learning and Individual Differences, 49, 162-170. https://doi.org/10.1016/j.lindif.2016.06.008.

Guo, J., Parker, P. D., Marsh, H. W., \& Morin, A. J. S. (2015). Achievement, motivation, and educational choices: A longitudinal study of expectancy and value using a multiplicative perspective. Developmental Psychology, 51(8), 1163-1176. https://doi.org/10.1037/a0039440.

Henning, M. A., \& Shulruf, B. (2011). Academic achievement: Changes in motivational beliefs and selfregulated learning strategies over time. Psychologia, 54, 135-144. https://doi.org/10.2117/psysoc. 2011.135.

Hu, L., \& Bentler, P. M. (1999). Cutoff criteria for fit indexes in covariance structure analysis: Conventional criteria versus new alternatives. Structural Equation Modeling: A Multidisciplinary Journal, 6, 1-55. https://doi.org/10.1080/10705519909540118.

Karlen, Y. (2016). Differences in students' metacognitive strategy knowledge, motivation, and strategy use: A typology of self-regulated learners. The Journal of Educational Research, 109(3), 253-265. https:// doi.org/10.1080/00220671.2014.942895.

Kauper, T., Retelsdorf, J., Bauer, J., Rösler, L., Möller, J., Prenzel, M. \& Drechsel, B. (2012). PaLea - Panel zum Lehramtsstudium. Skalendokumentation und Häufigkeitsauszählungen des BMBF-Projektes (2. Welle) [PaLea - Panel on teacher training. Scale documentation and frequency analysis of the BMBF project (2nd wave)]. Ipn.

Kryshko, O., Fleischer, J., Waldeyer, J., Wirth, J., \& Leutner, D. (2020). Do motivational regulation strategies contribute to university students' academic success? Learning and Individual Differences, 82, 101912. https://doi.org/10.1016/j.lindif.2020.101912.

Ljubin-Golub, T., Petričević, E., \& Rovan, D. (2019). The role of personality in motivational regulation and academic procrastination. Educational Psychology, 39, 550-568. https://doi.org/10.1080/01443410. 2018.1537479.

Marsh, H. W., Pekrun, R., Lichtenfeld, S., Guo, J., Arens, A. K., \& Murayama, K. (2016). Breaking the double-edged sword of effort/trying hard: Developmental equilibrium and longitudinal relations among effort, achievement, and academic self-concept. Developmental Psychology, 52, 1273-1290. https:// doi.org/10.1037/dev0000146. 
Marton, F., \& Säljö, R. (1984). Approaches to learning. In F. Marton, D. J. Hounsell, \& N. J. Entwistle (Eds.), The experience of learning (pp. 36-55). Scottish Academic Press.

McInerney, D. M., Cheng, R.W.-Y., Mok, M. M. C., \& Lam, A. K. H. (2012). Academic self-concept and learning strategies: Direction of effect on student academic achievement. Journal of Advanced Academics, 23, 249-269. https://doi.org/10.1177/1932202x12451020.

Muthén, L. K., \& Muthén, B. (1998-2021). Mplus user's guide. Muthén \& Muthén.

Ning, H. K., \& Downing, K. (2015). A latent profile analysis of university students' self-regulated learning strategies. Studies in Higher Education, 40(7), 1328-1346. https://doi.org/10.1080/03075079.2014. 880832.

Ommundsen, Y., Haugen, R., \& Lund, T. (2005). Academic self-concept, implicit theories of ability, and self-regulation strategies. Scandinavian Journal of Educational Research, 49, 461-474. https://doi.org/ $10.1080 / 00313830500267838$.

Park, S. (2015). Virtual avatar as an emotional scaffolding strategy to promote interest in online learning environment. In S. Tettegah \& M. Gartmeier (Eds.), Emotions, technology, design \& learning. Elsevier.

Park, S., \& Yun, H. (2017). Relationships between motivational strategies and cognitive learning in distance education courses. Distance Education, 38, 302-320. https://doi.org/10.1080/01587919.2017. 1369007.

Park, S., \& Yun, H. (2018). The influence of motivational regulation strategies on online students' behavioral, emotional, and cognitive engagement. American Journal of Distance Education, 32, 43-56. https://doi.org/10.1080/08923647.2018.1412738.

Park, S., \& Lim, J. (2020). Training motivational regulation skills through virtual avatars in online learning. In B. Hokanson, G. Clinton, A. A. Tawfik, A. Grincewicz, \& M. Schmidt (Eds.), Educational technology beyond content: A new focus for learning (pp. 217-231). Springer International Publishing.

Pintrich, P. R., \& Garcia, T. (2012). Self-regulated learning in college students: Knowledge, strategies, and motivation. In P. R. Pintrich, D. R. Brown, \& C. E. Weinstein (Eds.), Student motivation, cognition, and learning (pp. 129-150). Routledge.

Rodriguez, C. M. (2009). The impact of academic self-concept, expectations, and the choice of learning strategy on academic achievement: The case of business students. Higher Education Research \& Development, 28, 523-539. https://doi.org/10.1080/07294360903146841.

Schwinger, M., \& Stiensmeier-Pelster, J. (2012). Effects of motivational regulation on effort and achievement: A mediation model. International Journal of Educational Research, 56, 35-47. https://doi. org/10.1016/j.ijer.2012.07.005.

Schwinger, M., \& Otterpohl, N. (2017). Which one works best? Considering the relative importance of motivational regulation strategies. Learning and Individual Differences, 53, 122-132. https://doi. org/10.1016/j.lindif.2016.12.003.

Schwinger, M., von der Laden, T., \& Spinath, B. (2007). Strategien zur Motivationsregulation und ihre Erfassung [Motivational regulation strategies and their measurement]. Zeitschrift Für Entwicklungspsychologie Und Pädagogische Psychologie, 39, 57-69. https://doi.org/10.1026/0049-8637.39.2.57.

Schwinger, M., Steinmayr, R., \& Spinath, B. (2009). How do motivational regulation strategies affect achievement: Mediated by effort management and moderated by intelligence. Learning and Individual Differences, 19, 621-627. https://doi.org/10.1016/j.lindif.2009.08.006.

Smit, K., de Brabander, C.-J., Boekaerts, M., \& Martens, R. L. (2017). The self-regulation of motivation: Motivational strategies as mediator between motivational beliefs and engagement for learning. International Journal of Educational Research, 82, 124-134. https://doi.org/10.1016/j.ijer.2017.01.00.

Steuer, G., Engelschalk, T., Eckerlein, N., \& Dresel, M. (2019). Assessment and relationships of conditional motivational regulation strategy knowledge as an aspect of undergraduates' self-regulated learning competencies. Zeitschrift Für Pädagogische Psychologie, 33(2), 95-104. https://doi.org/ 10.1024/1010-0652/a000237.

Teng, L. S., \& Zhang, L. J. (2018). Effects of motivational regulation strategies on writing performance: A mediation model of self-regulated learning of writing in English as a second/foreign language. Metacognition and Learning, 13, 213-240. https://doi.org/10.1007/s11409-017-9171-4.

Trautwein, U., Marsh, H. W., Nagengast, B., Lüdtke, O., Nagy, G., \& Jonkmann, K. (2012). Probing for the multiplicative term in modern expectancy value theory: A latent interaction modeling study. Journal of Educational Psychology, 104(3), 763-777. https://doi.org/10.1037/a0027470.

Valentín, A., Mateos, P. M., González-Tablas, M. M., Pérez, L., López, E., \& García, I. (2013). Motivation and learning strategies in the use of ICTs among university students. Computers \& Education, 61, 52-58. https://doi.org/10.1016/j.compedu.2012.09.008. 
VanderStoep, S. W., \& Pintrich, P. R. (2008). Learning to learn: The skill and will of college success (2nd ed.). Prentice Hall.

Weinstein, C. E., \& Meyer, D. K. (1991). Cognitive learning strategies and college teaching. New Directions for Teaching and Learning, 45, 15-26. https://doi.org/10.1002/t1.37219914505.

Weinstein, C. E., Acee, T. W., \& Jung, J. (2011). Self-regulation and learning strategies. New Directions for Teaching and Learning, 126, 45-53. https://doi.org/10.1002/t1.443.

Wild, K.-P., \& Schiefele, U. (1994). Lernstrategien im Studium. Ergebnisse zur Faktorenstruktur und Reliabilität eines neuen Fragebogens [Learning strategies of university students: Factor structure and reliability of a new questionnaire]. Zeitschrift Für Differentielle Und Diagnostische Psychologie, $15,185-200$.

Wolters, C. A. (1999). The relation between high school students' motivational regulation and their use of learning strategies, effort, and classroom performance. Learning and Individual Differences, 11, 281-299. https://doi.org/10.1016/S1041-6080(99)80004-1.

Wolters, C. A., \& Benzon, M. B. (2013). Assessing and predicting college students' use of strategies for the self-regulation of motivation. The Journal of Experimental Education, 81(2), 199-221. https://doi.org/ 10.1080/00220973.2012.699901.

Yun, H., \& Park, S. (2020). Building a structural model of motivational regulation and learning engagement for undergraduate and graduate students in higher education. Studies in Higher Education, 45, 271-285. https://doi.org/10.1080/03075079.2018.1510910.

Zimmerman, B. J., \& Pons, M. M. (1986). Development of a structured interview for assessing student use of self-regulated learning strategies. American Educational Research Journal, 23, 614-628. https:// doi.org/10.3102/00028312023004614.

Publisher's Note Springer Nature remains neutral with regard to jurisdictional claims in published maps and institutional affiliations.

Annette Lohbeck. Faculty of Educational Sciences, University of Paderborn, Warburger Str. 100, 33098 Paderborn, Germany. Email: annette.lohbeck@uni-paderborn.de

Current themes of research of the authors:

Annette Lohbeck is interested in motivation, emotions, and self-concept of students and teachers. The key focus of her research is on the determinants and outcomes of students' and teachers' motivation, emotions, and self-concept.

The most relevant publications in the field of Psychology of Education of the authors of this article are listed below:

Lohbeck, A. (2020). Prüfungsangstprofile von Schülerinnen und Schülern und deren Zusammenhänge mit verschiedenen Schülermerkmalen [Test anxiety of students and its relations to various student characteristics]. Zeitschrift für Pädagogische Psychologie, O(0), 1-20. https://doi.org/10.1024/1010$0652 / \mathrm{a} 000289$.

Lohbeck, A. (2020). Does integration play a role? Academic self-concepts, self-esteem, and self-perceptions of social integration of elementary school children in inclusive and mainstream classes. Social Psychology of Education, 23(5), 1367-1384. https://doi.org/10.1007/s11218-020-09586-8.

Lohbeck, A. (2019). Social and dimensional comparison effects on academic self-concepts and self-perceptions of effort in elementary school children. Educational Psychology, 39, 133-150. https://doi.org/10.1080/ 01443410.2018 .1527018$.

Lohbeck, A. (2018). Freude am Sportunterricht - Welche Rolle spielen sportartspezifische Selbst $\neg$ konzepte und die wahrgenommene Lehrerfürsorglichkeit von Schülerinnen und Schülern? [ Joy of physical education - What role do sport-specific self-concepts and perceived teacher care of students play for joy of physical education in students?] Zeitschrift für Pädagogische Psychologie, 32, 117-132. https:// doi.org/10.1024/1010-0652/a000214.

Lohbeck, A., Engels, E. S. \& Freund, P. A. (2018). Assessing students' enjoyment in physical education: Measurement invariance across school tracks and relationships with grades. Journal of Psychoeducational Assessment, 0734282918804600. https://doi.org/10.1177/0734282918804600.

Lohbeck, A., Hagenauer, G. \& Frenzel, A. C. (2018). Teachers' self-concepts and emotions: Con $\neg$ cep $\neg$ tualization and relations. Teaching and Teacher Education, 70, 111-120. https://doi.org/10.1016/j.tate.2017.11.001. 
Lohbeck, A. \& Petermann, F. (2018). Factorial validity of the Anxiety Questionnaire for Students (AQS): Bifactor modeling and measurement invariance. Journal of Psychoeduca $\neg$ tional Assessment. https:// doi.org/10.1177/0734282918794834.

Lohbeck, A. \& Petermann, F. (2018). Cybervictimization, self-esteem, and social relationships among German secondary school students. Journal of School Violence, 17, 472-486. https://doi.org/10.1080/ 15388220.2018 .1428194$.

Lohbeck, A. (2017). Die individuell präferierte Bezugsnormorientierung und das Selbstkonzept von Grundschulkindern im Fach Mathematik. [Individually preferences for reference standard orientation and self-concept of elementary school children in mathematics]. Zeitschrift für Pädagogische Psycholo $\neg$ gie, 31, 1-17. https://doi.org/10.1024/1010-0652/a000199.

Lohbeck, A., Grube, D. \& Moschner, B. (2017). Academic self-concept and causal attributions for success and failure amongst elementary school children. International Journal of Early Years Education, 25, 190-203. https://doi.org/10.1080/09669760.2017.1301806.

Lohbeck, A. \& Möller, J. (2017). Social and dimensional comparison effects on math and reading selfconcepts of elementary school children. Learning and Individual Differences, 54, 73-81. https://doi. org/10.1016/j.lindif.2017.01.013.

Lohbeck, A. \& Petermann, F. (2017). Peer victimization, self-concept, and grades: The medi-ating role of self-concept. Deviant Behavior, 38, 1-14. https://doi.org/10.1080/01639625.2016.1197654.

Lohbeck, A., Tietjens, M., \& Bund, A. (2017). A short German Physical-Self-Concept Questionnaire for elementary school children (PSCQ-C): Factorial validity and measurement invariance across gender. Journal of Sports Sciences, 35, 1691-1696. https://doi.org/10.1080/02640414.2016.1230226.

Lohbeck, A. (2016). Self-concept and self-determination theory: math self-concept, motivation, and grades in elementary school children. Early Child Development and Care, 188, 1031-1044. https://doi.org/10. 1080/03004430.2016.1241778.

Lohbeck, A., Hagenauer, G. \& Moschner, B. (2016). Zum Zusammenspiel zwischen schulischem Selbstkonzept, Lernfreude, Konzentration und Schulleistungen im Grundschul $\neg$ al $\neg$ ter [On the interplay of academic self-concept, learning enjoyment, concentration and academic achievement at elementary school age]. Zeitschrift für Bildungsforschung, 6, 53-69. https://doi.org/10.1007/s35834-016-0147-2.

Lohbeck, A., Nitkowski, D. \& Petermann, F. (2016). A control-value theory approach: Relationships between academic self-concept, interest, and test anxiety in elementary school children. Child \& Youth Care Forum, 45, 1-18. https://doi.org/10.1007/s10566-016-9362-1.

Lohbeck, A., Schultheiß, J., Petermann, U. \& Petermann, F. (2016). Factor structure and measure $\neg$ ment invariance of the Students' Self-report Checklist of Social and Learning Behaviour (SSL). Learning and Individual Differences, 51, 314-321. https://doi.org/10.1016/j.lindif.2016.08.038.

Lohbeck, A., Tietjens, M. \& Bund, A. (2016). Physical self-concept and physical activity enjoy $\neg$ ment in elementary school children. Early Child Development and Care, 187, 1-10. https://doi.org/10.1080/ 03004430.2015.1132708.

Lohbeck, A., Petermann, F. \& Petermann, U. (2015). Selbsteinschätzungen zum Sozial- und Lern $\neg$ verhalten von Grundschulkindern der vierten Jahrgangsstufe [Self-assessments for social and learning behavior of fourth graders]. Zeitschrift für Entwicklungspsy $\neg$ chologie und Pädagogische Psychologie, 47, 1-13. https://doi.org/10.1026/0049-8637/A000118.

Lohbeck, A., Nitkowski, D., Petermann, F. \& Petermann, U. (2014). Erfassung von Schülerselbstein $\neg$ schätzungen zum schulbezogenen Sozial- und Lernverhalten: Validierung einer Schülerein $\neg$ schätzliste für Sozial- und Lernverhalten (SSL) [Assessment of students' self-concepts for school-related social and learning behaviour: Validation of the Self-Report Checklist for Social and Learning Behaviour (SSL)]. Zeitschrift für Erziehungswissenschaft, 17, 701-722. https://doi.org/10. 1007/s11618-014-0582-6.

Barbara Moschner. School of Educational and Social Sciences, Faculty of Educational Sciences, Carl Von Ossietzky University of Oldenburg, Ammerländer Heerstraße 114-118, 26129 Oldenburg, Germany. Email: barbara.moschner@uni-oldenburg.de

Current themes of research of the authors:

Barbara Moschner has also a keen interest in research on academic self-concept, motivation, and emotions, but also on cognitive learning strategies of students, especially in the university context. 
The most relevant publications in the field of Psychology of Education of the authors of this article are listed below:

Schlesier, J., Roden, I., \& Moschner, B. (2019). Emotion regulation in primary school children: A systematic review. Children and Youth Services Review, 100, 239-257. https://doi.org/10.1016/j.childyouth.2019. 02.044 .

Hagenauer, G., Gläser-Zikuda, M., \& Moschner, B. (2018). University students' emotions, life-satisfaction and study commitment: a self-determination theoretical perspective. Journal of Further and Higher Education, 42(6), 808-826. https://doi.org/10.1080/0309877X.2017.1323189.

Lohbeck, A., Hagenauer, G., Mühlig, A., Moschner, B. \& Gläser-Zikuda, M. (2016). Prokrastination bei Studierenden des Lehramts und der Erziehungswissenschaften [Procrastination in university students of teacher education and educational sciences]. Zeitschrift für Erziehungswissenschaft, 20, 521-536. https://doi.org/10.1007/s11618-016-0718-y1-16.

Lohbeck, A., Grube, D. \& Moschner, B. (2017). Academic self-concept and causal attributions for success and failure amongst elementary school children. International Journal of Early Years Education, 25, 190-203. https://doi.org/10.1080/09669760.2017.1301806.

Lohbeck, A., Hagenauer, G. \& Moschner, B. (2016). Zum Zusammenspiel zwischen schulischem Selbstkonzept, Lernfreude, Konzentration und Schulleistungen im Grundschul $\neg$ al $\neg$ ter [On the interplay of academic self-concept, learning enjoyment, concentration and academic achievement at elementary school age]. Zeitschrift für Bildungsforschung, 6, 53-69. https://doi.org/10.1007/s35834-016-0147-2. 